\title{
Reading Anxiety Among Chinese Exchange Students in a Study-abroad Context
}

\author{
Li Lijun $^{1}$ \\ ${ }^{1}$ School of Law and Humanity, China University of Mining and Technology, Beijing, China \\ Correspondence: Li Lijun, School of Law and Humanity, China University of Mining and Technology, Beijing, \\ China.
}

Received: July 13, 2019 Accepted: August 22, 2019 Online Published: August 24, 2019

doi: 10.5539/elt.v12n9p96 URL: https://doi.org/10.5539/elt.v12n9p96

\begin{abstract}
This study presents the results of an investigation into L2 reading anxiety among eight Chinese exchange students who participate in a one-year program at an American University. Foreign Language Reading Anxiety Scale (FLRAS) is used as a measurement of reading anxiety. Data are also collected from semi-structured interviews, syllabus of all six specialized courses participants have taken during the academic year and their final scores. The study finds: 1) all participants experience a rather high level of reading anxiety; 2) despite such anxiety, participants perform well in all major courses; 3) underlying causes for reading anxiety include content knowledge, unpreparedness of cultural difference and general negative feeling of studying a foreign language. Based on the research findings, suggestions are given to improve the overall efficacy of such exchange program, aiming to benefit all immediate parties involved.
\end{abstract}

Keywords: L2 reading anxiety, Chinese exchange students, content knowledge, cultural difference

\section{Introduction}

One of the most widely studied concepts in learning a language is the notion of anxiety. It is common that research in this field has studied the possible relationship between anxiety and performance, and its interference in language competence (Horwitz et al., 1986; Horwitz, 2001). The majority of studies have focused on the anxiety related to oral performance and listening (Horwitz et al., 1986; Phillips, 1992; Price, 1991; Young, 1991), while reading anxiety has been generally neglected until the late 20th century. Zbornik and Wallbrown (1991) are the first to introduce the concept of reading anxiety. They propose reading anxiety represents a specific aspect of general anxiety and state the anxiety with negative feelings, such as the lack of self-confidence or the fear of making mistakes in after-reading tasks, can easily cause misinterpretation during the reading process. It is also proven that a high level of reading anxiety usually distracts language learners' attention from meaning and may further undermine learners' foreign language reading development in the long run (Gass \& Selinker, 2001).

Existing literature has shown that learning foreign language in a study-abroad context can help students gain their language achievement (Freed, 1995), but it's also argued students may perceive their anxiety differently. To clear the mist, it is necessary to investigate how reading anxiety is influenced by relevant factors, such as learners' previous learning background and their epistemological experiences. Relevant studies rarely focus on Chinese exchange students, especially those sponsored to participate in a short-term exchange program. As recent years see a rapid increase number of Chinese exchange students, with 12,000 students sponsored in the year 2018 recorded by the Ministry of Education, it calls for attention to study their academic development in a foreign setting. Hence, the present study is to investigate the reading anxiety of Chinese exchange students studying abroad in an English-speaking country, explore its possible impacts and analyze its relation to students' academic achievement, hoping for both better understanding this particular group of learners and filling in the gap of this research area.

\section{Reading Anxiety and Related Studies}

Foreign language anxiety is a form of situation-specific anxiety (Horwitz et al., 1986), long considered to be more associated with productive skills. Only in recent years, anxiety is more often connected with receptive skills, typically of reading. Different types of foreign language anxiety have been identified as variables. Jalongo and Hirsh (2010) addressed L2 reading anxiety is a kind of specific phobia, a situational type and an unpleasant 
emotional reaction toward reading which has physical and cognitive reactions. Liu and Sammy (2012) pointed out that $\mathrm{L} 2$ reading anxiety is complicated because it is affected by a complex mix of linguistic and nonlinguistic factors inextricably linked together.

To find out possible effects of anxiety, Cohen and Norst (1989) studied language learning diaries of L2 students. In their diaries, participants express fears and anxieties of performing in front of their classmates and teachers. Their fears and worries are not only demonstrated in words like embarrassment, resentment, frustration, anger, paranoid, guilty or unnerving but also reflected by their physical actions, such as sweating, trembling hands, and strong heartbeat. However, there are two noticeable opposing opinions offered about language learners, learning outcomes. The first is that anxiety might cause competitiveness. Reading anxiety might develop a stronger stimulus in learners, desire for better achievements (Daley, 1999). The other opinion is the competitiveness has a negative relationship with anxiety, to raise it up, which means anxiety can impede learners from gaining their ideal aims (Saito et al., 1999).

Saito et al. (1999) introduced the construct of "foreign language reading anxiety". They applied both Foreign Language Reading Anxiety Scale (FLRAS) developed on themselves and Foreign Language Class Anxiety Scale (FLCAS) designed by Horwitz et al. in 1986 to test the reading anxiety and class anxiety of 383 students respectively. The results proved that reading anxiety is distinct from general types of foreign language anxiety, and students' increasing reading anxiety leads to a decrease in their final grades. Sellers (2000) studied the impact of anxiety on reading comprehension and the reading process, finding that the higher level of anxiety, the worse subjects perform at recollecting tasks.

As for the causes of reading anxiety, Saito et al. (1999) reported that two aspects of L2 reading have a significant effect on eliciting anxiety: unfamiliar scripts of writing systems and unfamiliar cultural materials. They also noted the causes and manifestations of reading anxiety could be more subtle and complex than their original hypothesis, suggesting the need to investigate the effects of other variables. Experience with the target country is one commonly visited variable. Studies (Aida, 1994; Huang, 2001; Xiao \& Wong, 2014) show experience in the target country greatly reduced students' general FL anxiety levels. Zhao et al. (2013) investigated the relationship between experience with the target country and FL reading anxiety. They stated students who had been to China to study Chinese demonstrate a much lower level of FL reading anxiety compared to students who had not. Besides, they also reported two key influencers, one being the loose connection between their writing system and the real pronunciation, the other learners' lack of background knowledge in curricular contents. Brantmeier (2005) examined 92 students on reading comprehension of specific foreign language courses, concluding that students show different levels of reading anxiety with different courses, which recognizes text features as major causes. Jing (2017) studied Chinese L2 learners and identified major sources of L2 reading anxiety, including worries relating to comprehension, unfamiliar topics, unknown pronunciation, and feeling uncomfortable reading aloud.

Among most relevant research on reading anxiety, quite a number investigate how reading anxiety appears by a once-for-all questionnaire survey or correlating the data with learners' overall language learning outcomes. Relevant factors such as text features of reading materials and their experience in the exotic academic setting are under-explored. Besides, L2 learners involved in a short-term exchange program are never focalized in any study. This population may project different insights into L2 reading anxiety, as reading in their sense does not only imply a heavy reading load in L2 but more often involves in more diversified and complex content knowledge. They may involve in an academic program and curricular setting which in an overall sense differ a lot from those at their home university, thus exert influence on their reading anxiety. Therefore, the present study focuses on these special L2ers, a group of Chinese exchange students, in hope to reveal the state of their reading anxiety, explore its underlying causes and how such affection influences their academic performance.

\section{Research Design}

The present study examines FL reading anxiety of eight Chinese exchange students who sign in a one-year exchange program at an American university. The following questions will be explored:

1) How does FL reading anxiety demonstrate among the participants?

2) How do the participants perform academically with the presence of reading anxiety?

3) What might be the underlying causes of their reading anxiety?

\subsection{Participants}

The participants exhaust the total of eight Chinese exchange students (S1-S8) proceeding their study on Criminal Justice at an American University. The researcher personally got known the participants while she herself 
worked as an exchange scholar at the same university. Upon their arrival, some participants talked about their anxiety in doing reading tasks during a few casual meeting with the researcher. The latter out of her own experience of learning L2 offered some suggestions to help them smooth over, during which they built trust in each other. And the participants all consented to take part in the research when the researcher introduced the design. Upon finishing the data analysis part, the researcher did member check and a few minor revisions were carried to keep the data authentic.

Different from other studies on reading anxiety, the participants in this study all come from the same discipline. One advantage is the elimination of possible impact that various academic program might bring on their reading anxiety. Furthermore, those participants share a common background before their departure to America. They all major in Criminal Justice back in their home university and rank the top 10 in GPA in the first two years of university study. None of them has previous experience either of living or studying in an abroad-context. And all eight participants (four females: S1, S2, S3, S4; four males: S5, S6, S7, S8;) have studied English for over ten years and passed TOEFL with an average of 80 before arrival.

\subsection{Instruments}

The instruments used for data collection include one questionnaire-Foreign Language Reading Anxiety Scale (FLRAS), a semi-structured interview and syllabus of six specialized courses the participants have taken under the exchange program.

\section{Instrument 1: Foreign Language Reading Anxiety Scale (FLRAS)}

Foreign Language Reading Anxiety Scale (FLRAS) is adapted from Saito et al. (1999) to elicit participants' self-reported anxiety. This instrument contains 20 items, each answered according to a 5-point Likert-type scale: $1=$ Strongly Disagree, $2=$ Disagree, $3=$ neither Agree nor Disagree, $4=$ Agree, $5=$ Strongly Agree. Each item has a numerical value and all items would be added up for calculating the score of this questionnaire. The total score of FLRAS ranges from 20 to 100. The higher score implies more and stronger reading anxiety the participants experience. The reliability of survey items is measured: Cronbach $\alpha=0.802$, which shows there is an internal consistency among the questionnaire items. By the end of the second semester. all participants are invited to respond to the questionnaire in the classroom where they have just finished their afternoon session. They return it timely and data is processed right after the collection.

Instrument 2: Semi-structured Interview

The semi-structured interview is conducted for an in-depth analysis of the quantitative data. Upon finishing all finals and learning about the results, all participants take part in the interview via the internet in one-on-one communication with the researcher. The interview mainly focuses on how participants view reading anxiety, its possible sources and impacts. Participants are also asked to comment on the six specialized courses they take during the academic year.

\section{Instrument 3: Syllabus of Specialized Courses}

All participants have taken six specialized courses during the academic year. The syllabus of these courses is analyzed to help better explore the research questions. Table 1 summarizes curricular information about these courses.

Table 1. Curricular information of six specialized courses

\begin{tabular}{|c|c|c|c|}
\hline Course Title & Teaching Material & Teaching Activities & Assessment \\
\hline $\begin{array}{l}\text { Family Violence } \\
(\mathrm{FV})\end{array}$ & Three textbooks & $\begin{array}{l}\text { Several online classes; } \\
\text { Requiring taking notes; } \\
\text { Exchanging ideas in class; }\end{array}$ & $\begin{array}{l}\text { Open-book tests; Flexible } \\
\text { question types }\end{array}$ \\
\hline $\begin{array}{l}\text { Victimology } \\
(\mathrm{VICT})\end{array}$ & $\begin{array}{l}\text { One textbook; three } \\
\text { extensive reading } \\
\text { materials; supplementary } \\
\text { in-class reading materials }\end{array}$ & $\begin{array}{l}\text { Combined with video and } \\
\text { audio materials; }\end{array}$ & $\begin{array}{l}\text { Closed-book tests; Multiple } \\
\text { choices; True or False } \\
\text { questions; 2-page papers; }\end{array}$ \\
\hline $\begin{array}{l}\text { Zombies and } \\
\text { Homeland } \\
\text { Security } \\
\text { (Z\&HS) }\end{array}$ & Five textbooks; & $\begin{array}{l}\text { Flexible class arrangement; } \\
\text { In-class reading tests; }\end{array}$ & $\begin{array}{l}\text { Closed-book tests; Multiple } \\
\text { choices; True or False } \\
\text { questions; one paper over } \\
5000 \text { words; }\end{array}$ \\
\hline Criminal Justice & No textbook; & Working in groups; Reports \& & Online open-book tests; \\
\hline
\end{tabular}




\begin{tabular}{|c|c|c|c|}
\hline $\begin{array}{l}\& \\
\text { Diversity } \\
(\mathrm{CJ} \& \mathrm{SD})\end{array}$ & Over six extensive reading & Journal every day; & Group project; \\
\hline $\begin{array}{l}\text { Texas } \\
\text { Government } \\
\text { (TG) }\end{array}$ & $\begin{array}{l}\text { One textbook; } \\
\text { supplementary reading } \\
\text { materials }\end{array}$ & $\begin{array}{l}\text { Questionnaires on advice; } \\
\text { Requiring following local } \\
\text { policy; Questions for students } \\
\text { to take turns to answer; }\end{array}$ & $\begin{array}{l}\text { Closed-book quiz at the } \\
\text { beginning of each lesson; } \\
\text { Online final open-book } \\
\text { tests; }\end{array}$ \\
\hline $\begin{array}{l}\text { Introduction to } \\
\text { Methods of } \\
\text { Research } \\
\text { (IMR) }\end{array}$ & One textbook & $\begin{array}{l}\text { Working in a group; Requiring } \\
\text { presentation on reading in } \\
\text { class; Questions on a research } \\
\text { project; }\end{array}$ & $\begin{array}{l}\text { One paper; Closed-book } \\
\text { tests (writing articles, } \\
\text { short-answer questions); }\end{array}$ \\
\hline
\end{tabular}

\subsection{Data Analysis}

This study resorts to a mixed research design. First a questionnaire survey is conducted and all the data are coded and then analyzed through SPSS22.0. Descriptive statistics such as frequencies are computed to display the participants' overall responses to FLRAS. Then qualitative data are collected through semi-structured interview and curricular information of six specialized courses. The interview is carried out and recorded by the end of the academic year. It is transcribed immediately afterward and doubled checked by both the researcher and participants for possible missings or errors. Key information of the six specialized courses is analyzed with reference to the research questions.

\section{Research Findings}

The results of the research will be organized in accordance with the research questions.

\subsection{The Overall Demonstration of L2 Reading Anxiety}

Foreign Language Reading Anxiety Scale (FLRAS) contains 20 items to investigate participants' reading anxiety levels. Table 2 shows the descriptive statistics with SPSS 22.0, the average mean among the 20 items being 2.76 .

Table 2. Descriptive data of FLRAS

\begin{tabular}{llllll}
\hline Item & Mean & SD & Item & Mean & SD \\
\hline 2 & $\mathbf{3 . 7 5}$ & 1.28 & 8 & 2.63 & 0.92 \\
1 & $\mathbf{3 . 6 3}$ & 1.19 & 18 & 2.63 & 0.92 \\
6 & $\mathbf{3 . 5 0}$ & 0.76 & 10 & 2.63 & 0.74 \\
20 & $\mathbf{3 . 2 5}$ & 1.39 & 15 & 2.50 & 1.07 \\
5 & $\mathbf{3 . 1 3}$ & 1.13 & 4 & 2.38 & 0.74 \\
7 & $\mathbf{3 . 1 3}$ & 0.83 & 12 & 2.25 & 0.46 \\
19 & $\mathbf{3 . 0 0}$ & 1.07 & 16 & 2.13 & 0.99 \\
17 & $\mathbf{2 . 8 8}$ & 1.25 & 9 & 2.00 & 0.53 \\
3 & $\mathbf{2 . 8 8}$ & 0.83 & 14 & 1.38 & 0.52 \\
11 & 2.75 & 0.89 & Average & 2.76 & 0.91 \\
13 & 2.75 & 0.71 & Sum & 55.18 & 18.22 \\
\hline
\end{tabular}

Nine topic-related items present a high mean than the average. Item 2 "When reading English, I often understand the words but still cannot quite understand what the author is saying" scores the highest mean of 3.75 , showing participants usually experience reading anxiety when they fail to understand the contents of the reading material, despite their overall language proficiency. Similarly Item 5 "I am nervous when I am reading a passage in English when I am not familiar with the topic" further states lack of content knowledge affects reading anxiety to a great deal. 
The second primary source is converging on the rudiment role of cultural knowledge in reading anxiety, as indicated in Item 20 "You have to know so much about English history and culture in order to read English," and Item 19 "English culture and ideas seem very foreign to me." These items stress familiarity with the local environment and target culture is somewhat necessary to cushion their landing into the exotic setting.

The third primary source is strongly supported by Item 1 "I get upset when I'm not sure whether I understand what I am reading in English", Item 6 "I get upset whenever I encounter unknown grammar when reading English", Item 7 "When reading English, I get nervous and confused when I don't understand every word" and Item 17 "I don't mind reading to myself, but I feel very uncomfortable when I have read English aloud". Vocabulary like "upset," "nervous," "confused" and "uncomfortable" frequently repeat themselves in the questionnaire items, which speak of negative feelings that participants experience when reading in FL.

Such intense anxiety also exposes itself in the semi-structured interview. The first interview question asks whether the participants are experiencing reading anxiety, unanimously all eight participants reckon their reading anxiety, describing it as a kind of negative emotion, which very much degrades their learning motivation as well as learning performance both in class and at exams.

\subsection{Participants' Academic Performance}

Table 3. Participants' academic performance of six specialized courses

\begin{tabular}{lllllllll}
\hline Course & $\mathrm{S} 1 / \mathrm{F}$ & $\mathrm{S} 2 / \mathrm{F}$ & $\mathrm{S} 3 / \mathrm{F}$ & $\mathrm{S} 4 / \mathrm{F}$ & $\mathrm{S} 5 / \mathrm{M}$ & $\mathrm{S} 6 / \mathrm{M}$ & $\mathrm{S} 7 / \mathrm{M}$ & $\mathrm{S} 8 / \mathrm{M}$ \\
\hline Family Violence & $\mathrm{A}$ & $\mathrm{A}$ & $\mathrm{A}$ & $\mathrm{A}$ & $\mathrm{A}$ & $\mathrm{A}$ & $\mathrm{A}$ & $\mathrm{A}$ \\
Victimology & $\mathrm{B} / 85$ & $\mathrm{~B} / 86$ & $\mathrm{~B} / 88$ & $\mathrm{~B} / 85$ & $\mathrm{~B} / 84$ & $\mathrm{~A} / 90$ & $\mathrm{~A} / 94$ & $\mathrm{~B} / 87$ \\
Zombies and Homeland Security & $\mathrm{A} / 91$ & $\mathrm{~A} / 90$ & $\mathrm{~A} / 95$ & $\mathrm{~A} / 91$ & $\mathrm{~B} / 88$ & $\mathrm{~B} / 86$ & $\mathrm{~A} / 98$ & $\mathrm{~A} / 93$ \\
Criminal Justice \& Social Diversity & $\mathrm{B} / 87$ & $\mathrm{~A} / 91$ & $\mathrm{~A} / 95$ & $\mathrm{~A} / 97$ & $\mathrm{~A} / 94$ & $\mathrm{~A} / 91$ & $\mathrm{~A} / 95$ & $\mathrm{~A} / 92$ \\
Texas Government & $\mathrm{A}$ & $\mathrm{A}$ & $\mathrm{A}$ & $\mathrm{A}$ & $\mathrm{B}$ & $\mathrm{A}$ & $\mathrm{A}$ & $\mathrm{B}$ \\
Intro. to Methods of Research & $\mathrm{A} / 92$ & $\mathrm{~B} / 88$ & $\mathrm{~A} / 92$ & $\mathrm{~A} / 90$ & $\mathrm{~B} / 81$ & $\mathrm{~B} / 83$ & $\mathrm{~A} / 91$ & $\mathrm{~B} / 81$ \\
Average Final Score & 90.83 & 90.83 & 93.33 & 92.17 & 87.83 & 90.00 & 94.67 & 88.83 \\
Rank among Peers & $24 / 189$ & $18 / 189$ & $6 / 189$ & $9 / 189$ & $27 / 189$ & $20 / 189$ & $2 / 189$ & $22 / 189$ \\
\hline
\end{tabular}

Table 3 records participants' academic achievements of six specialized courses. Though they claim in the interview that high-level reading anxiety restricts their performance both in class and during exams, all eight participants rank among the top $15 \%$ of the grade. One first reason to explain such performance might be the participants have already gone through a very fierce competition when applying for the exchange program. All of them rank the top 5\% at their home university, with an average TOEFL score of 80 , which lays a solid basis of both language and specialized courses. Another reason is disclosed in the interview. Participants say before and during exams they manage to convert negative feeling of anxiety into positive stimuli. They talk about their instinctive fear of failing in exams, and the determination to end in excellence, which enables them to see anxiety as a push, a strong sense of fighting back, of conquering the mission impossible. For instance, S6 says that he considers reading anxiety as an enemy, and he actively seeks for others' advice to improve his reading strategies in order to repel the enemy. S7 expresses that he wants perfect final achievement, so he becomes conscientious and devotes more to the courses he is not good at, take Zombies for example. Such conversion of anxiety awards him No.1 in the final.

\subsection{Underlying Causes of L2 Reading Anxiety}

During the interview, participants all relate to the connection between their reading anxiety and the reading materials they are assigned. S7 recalls his experience when asked to summarize or comment on the reading material, saying "I get sweaty palms and butterflies in my stomach." Besides the unfamiliarity of content knowledge, the reading load is seen as rather demanding with most courses. Table 2 shows, aside from the course IMR, all other five major courses require plenty of reading, covering not only textbooks, but supplementary reading materials as well. Comparatively, claimed the participants, most specialized courses at their home university assign one single textbook and reading it thoroughly can guarantee a pass in the exam. S1 comments she feels quite worried with CJ\&SD, relating the long and complicated reading materials are beyond her, curtailing her self-confidence. She feels frustration and dislikes that course. The reading load of VICT has 
been frequently recalled during the interview. This course requires supplementary in-class reading materials, wich were commented by all subjects as "a daunting task," "sensational," "unbelievable," "alarming," etc., drawing a picture of a mission impossible. The in-class reading is to be done strictly in class, rejecting any preparation, consultation of dictionary or discussion with peers. No wonder it becomes such a "bitter" memory, quoting their word. It is also this course that participants generally fail to perform well, recording $6 \mathrm{Bs}$ in the final.

Cultural difference demonstrates as one potential cause for reading anxiety both from questionnaire survey and the interview. Participants say classroom culture might play an impending role in their reading comprehension. They describe what usually happens in their American classrooms: we are often asked to state their perspectives, build links between materials, discuss with our peers, which is very different from what we have been experiencing back in China. S4 states that her reading anxiety often manifests as lack of confidence to read passages out, mainly when being asked to express a view on the subject matter, for "Back in my country, there is not much discussion in class; even when there happens a discussion with my classmates, we are expected to do that in our mother language, Chinese."

Group discussion, one of the most favorite activities in American universities, surprisingly acts as a double-edged sword in the present case. S2 and S7 find working-in-group raise their reading anxiety while S5 confirms its positive effect. All participants related to the course IMR. S2 says that she feels quite pressured when groups are asked to answer questions in turn regarding reading materials. Similarly, S7 feels upset in class when asked to exchange ideas and views about the reading material within and between groups as he does not always understand other students' opinion. However, S5's voice is somewhat different, who takes group work as an excellent opportunity to help him improve reading comprehension and language competence.

Reading in a foreign language also restates itself as a source of anxiety during the structured interview, indicating participants are afraid of linguistic difficulties, being it vocabulary or grammar. Such negative feeling may also present as fear, frustration, or sense of failure, symbolizing anxiety in one way or another. S5 addresses Z\&HS has assigned five textbooks, with a large number of new words on each page. He recalls in the interview: "I often spend much time referring to the dictionary, but still cannot understand the meaning, then I lose confidence in this course and gets a low score in the exam." S8 finds out that English is never that kind of language: once you know each word, you understand the meaning of the sentence or paragraph. He mentions quite often he fails to figure out what the author wants to say even when he knows every word, which is typically true with the vast number of argumentative essays assigned in Z\&HS. S2 has a common ground as S8, addressing her lousy habit that if she cannot understand one sentence in the English article, she would keep thinking about it and feel resistant to move on. This habit slows down her reading speed and increases her reading anxiety. We see here that participants might get involved into a vicious circle; once they experience reading anxiety, it will be hard for them to comprehend the reading material; when there happens a problem in understanding, they tend to feel more anxious and pressured, demotivated to proceed with reading. 5. Discussion

The descriptive data of the questionnaire survey shows all participants are experiencing reading anxiety in such a study-abroad context. The average FLRAS sum in the present study is 55.18 , slightly higher than 52.9 reported in Saito et al (1999). Why do the participants demonstrate more intense reading anxiety? Other than culture-related items which have been frequently converged as significant contributors in other studies (Saito et al., 1999; Sellers, 2000), this study finds topic-related items occupy the top few of higher means, which speaks of content knowledge as a significant predictor of reading anxiety. This is no myth when observing closely the English reading materials participants engage in before landing on foreign land and the way they process these materials. Mostly the reading materials are adapted or abridged versions of the source texts. Topics are very often familiar ones, such as campus life, shopping, traveling and hobbies rather than introducing content knowledge. Similarly unfamiliar topics are identified by Jing (2017) as one major source of FL reading anxiety. Besides, text features are undeniably major causes of FL reading anxiety as the assigned readings of specialized courses are unanimously authentic materials, featuring specialized vocabulary and complex syntactical patterns. Such findings are supported by Brantmeier (2005) and Genç (2016) who declare students' reading anxiety is the highest in items related to the nature of the text. In other words, L2 learners experience lower level of anxiety when they are familiar with reading texts as they can understand easily by looking at the genre of the text.

Another cause that provokes reading anxiety involves the negative feeling of reading in a foreign language. The participants report an increasing level of anxiety while reading in English. Such negative feeling intensifies when they encounter unknown terminologies or grammatical patterns that they do not have a command of. They simply get anxious upon laying on the lengthy and authentic reading assignment, thus comprehension is negatively affected (Genç, 2016; Jing, 2017). Jing (2017) reports when learners spend too many cognitive 
resources on lower-level word processing, they are less likely to understand the meaning of the reading passage. Without necessary knowledge of specialized vocabulary and the linguistic features of the text, the participants would be missing global understanding of the discourse. Though the participants have passed TOEFL with an average of 80, they still find authentic texts rather challenging. This is supported by Brantmeier (2005) and Jing (2017) who both find more advanced FL learners experience higher level reading anxiety as authentic texts usually mean more advanced vocabulary and grammar, and therefore require more resources from readers to comprehend the messages of the passage, thus raising the potential for a higher level of anxiety.

Lack of target cultural knowledge explains strongly the anxiety participants have gone through. Upon arrival they find themselves submerged in piles of reading materials, followed with requirements of thorough analysis, group discussion, oral presentation or paper test. The participants recall in the interview the more they want to perform well, the more anxious they feel at reading. This again proves that oral presentation and speaking English in the face of peers are very likely to bring along anxiety (Woodrow, 2006; Kim, 2009; Joo \& Damron, 2015). The reading tasks are not what the participants got used to in their home culture. Compared with their NS counterparts, they prefer a more self-centered learning style. They are more ready to read on themselves or write a follow-up essay. Classroom discussion might disturb their reading efficiency and make them more anxious. Being more anxious in turn decreases their reading efficiency. Such a vicious cycle is explained in the self-efficacy theory proposed by Bandura (1977), stating that learners with low self-esteem may suffer from frustration and anxiety. Genç (2016) also states the reading tasks as major sources of anxiety. He finds among his subjects the fear of making mistakes while doing the comprehension checks as well as being evaluated negatively in terms of English language abilities by the instructors and peers.

Despite of the general demonstration of reading anxiety among participants and the self-detected causes, the participants unexceptionally have performed well in the specialized courses. They explain the use of some learning strategies during the interview. S1 presents herself as a typical example. Her FLRAS is the highest, but her average final score ranks the fourth among all subjects and 24 in the grade. She talks about her learning experience during the interview which depicts her being good at communicating with others and solving the problem with teamwork. She says "at the beginning of the academic term, I find the reading materials of TG too difficult for me. I find a classmate who is good at this course and ask for his advice". That classmate tells her that if she wants to understand clearly about such political essays, she needs to get familiarized with the particular vocabulary. S1 then asks other Chinese exchange students to work together on the specialized vocabulary, which helps her a lot in reducing reading anxiety and improving her exam grades. Similarly other participants also actively resort to different strategies to help reduce their reading anxiety and thus improve their overall academic performance. Take S7 as an example, he reads the local newspaper every day to enrich his knowledge of local policies. S2 \& S5 work to pick up their reading speed, training themselves quickly to locate topic sentences, find keywords, etc., which improves their performance at exams. S4 likes drawing and writing down essential information when reading. Besides, she prefers to remember new words within sentences. The context helps her understand the words, meaning and learn their usages rapidly. S3, S5, S6 \& S8 all devote much time to read both extensively and intensively, speaking of their belief that overall English proficiency is the key to relieve reading anxiety and achieve a satisfactory outcome in the final exams. By applying effective learning strategies, L2 learners reduce their L2 reading anxiety, thus enchance their academic performance, which is supported in relevant studies (Jing, 2017; Joo \& Damron, 2015; Kim, 2009; Liu \& Sammy, 2012).

\section{Conclusion}

The present study casts light on both theoretical and empirical studies of FL reading anxiety with a singular focus on short-term exchange students. As Cheng (2006) points out in his study, differing from common overseas students, exchange students usually experience a shorter learning period abroad which may result in more intense demonstration of emotions affecting their academic performance. Though this particular population has for long gone unnoticed, its soaring number in recent years is calling for equal attention to maximize students' learning outcome and ensure the utmost efficiency of the exchange program. Based on multi-faceted data, this study unveils the general demonstration of reading anxiety among participants and explores the underlying causes for such anxiety. Content knowledge is found to be one different cause of anxiety, which suggests their home universities may offer some introductory or elementary specialized courses in English to familiarize students with specialized vocabulary and text features.

Meanwhile, if teachers at the host universities are also aware of the anxiety exchange students are experiencing, they could also help exchange students to overcome cultural difference. The teaching of culture is to be multi-dimensional, integrating explanation of theories and analysis of real-life cases. If possible, try to create chances for students to experience different cultures, for instance attending lectures given by foreign experts, 
joining in cultural-related activities, having a language partner, etc.. Such efforts will inevitably reduce the reading anxiety in a different learning setting.

Finally, the ultimate aim of education is to cultivate students with independent thinking, self-esteem, and responsibility. The traditional Chinese education strongly criticized though, still have impacts on the parties involved in one way or another. Students as bearers of such tradition, are less ready to think and read critically, express themselves in public, work cooperatively with a group, motivate themselves with a long-term goal. When the workload becomes demanding and the learning setting verifies, they would inevitably suffer from high-level of anxiety, as shown among the participants of this study. Therefore, it is also suggestible that their voice and individuality are to be valued at any stage of education.

\section{References}

Aida, Y. (1994). Examination of Horwitz, Horwitz, and Cope, s construct of foreign language anxiety: The case of students of Japanese. The Modern Language Journal, 78, 155-168. https://doi.org/10.1111/j.1540 $-4781.1994 . t b 02026 . x$

Bandura A. (1977). Self-efficacy: Towards a unifying theory of behavior change. Psychological Review, 2, 191-215. https://doi.org/10.1037/0033-295X.84.2.191

Brantmeier, C. (2005). Anxiety about L2 reading or L2 reading task? A study with advanced language. The Reading Matrix, 5, 67-84.

Cheng, A. C. (2006). Effects of differentiated curriculum and instruction on Taiwanese EFL students, motivation, anxiety, and interest. Unpublished doctoral dissertation, University of Southern California.

Cohen, Y., \& Norst, M. J. (1989). Fear, dependence, and loss of self-esteem: Affective barriers in second language learning among adults. RELC Journal, 20, 61-77. https://doi.org/10.1177/003368828902000206

Daley, O. (1999). Nothing succeeds like Linguistic competence. In G. M. Blue (Ed.), Language, learning, and success. London. Modern English Publications: British Council.

Freed, B. F. (1995). Language learning and study abroad. In B. F. Freed (Ed.), Second language acquisition in a study-abroad context. Philadelphia, PA: John Benjamins. https://doi.org/10.1075/sibil.9

Gass, S. M., \& Selinker. L. (2001). Second language acquisition: An introductory course. Mahwah: Lawrence Erlbaum Associates.

Genç, G. (2016). Can ambiguity tolerance, success in reading, and gender predict the foreign language reading anxiety? Journal of Language \& Linguistics Studies, 12(2), 135-151.

Horwitz, E. K. (2001). Language anxiety and achievement. Annual Review of Applied Linguistics, 1, 112-126. https://doi.org/10.1017/S0267190501000071

Horwitz, E. K., Horwitz, M. B., \& Cope, J. A. (1986). Foreign language classroom anxiety. The Modern Language Journal, 70, 125-132. https://doi.org/10.1111/j.1540-4781.1986.tb05256.x

Huang, H. Y. (2001). Chinese university foreign language students, anxiety about reading in English. (Unpublished doctoral dissertation). Washington State University, Pullman.

Jalongo, M. R., \& Hirsh, R. A. (2010). Understanding reading anxiety: New insights from neuroscience. Early Childhood Education Journal, 37, 431-435. https://doi.org/10.1007/s10643-010-0381-5

Kim, S. (2009). Questioning the stability of foreign language classroom anxiety and motivation across different classroom contexts. Foreign Language Annals, 1, 138-157. https://doi.org/10.1111/j.1944-9720.2009. 01012.x

Jing, Z. (2017). Foreign language reading anxiety in a Chinese as a foreign language context. Reading in a Foreign Language, 29(1), 155-173.

Joo, K. Y., \& Damron J. (2015). Foreign language reading anxiety: Korean as a foreign language in the United States. Studies in Linguistics, 32, 23-42.

Liu, Y., \& Sammy K. K. (2012). Survey on anxiety in reading Chinese-English syntactic differences: A case of English reading anxiety in Taiwanese university students. Theory and Practice in Language Studies, 2, 1363-1369. https://doi.org/10.4304/tpls.2.7.1363-1369

Phillips, E. (1992). The effect of language anxiety on students, oral test performance and attitudes. Modern Language Journal, 76, 14-26. https://doi.org/10.1111/j.1540-4781.1992.tb02573.x 
Price, M. L. (1991).The subjective experience of foreign language anxiety: Interviews with highly anxious students. In E. K. Horwitz (Ed.), Language anxiety: From theory and research to classroom applications (pp. 101-108). Englewood Cliffs, NJ: Prentice-Hall.

Saito, Y., Horwitz, E. K., \& Garza, T. J. (1999). Foreign language reading anxiety. The Modern Language Journal, 83, 202-218. https://doi.org/10.1111/0026-7902.00016

Sellers, V. D. (2000). Anxiety and reading comprehension in Spanish as a foreign language. Foreign Language Annals, 35, 512-520. https://doi.org/10.1111/j.1944-9720.2000.tb01995.x

Woodrow, L. (2006). Anxiety and speaking English as a second language. RELC Journal, 3, 308-328. https://doi.org/10.1177/0033688206071315

Xiao, Y., \& Wong, K. F. (2014). Exploring heritage language anxiety: A study of Chinese heritage language learners. The Modern Language Journal, 98, 589-611. https://doi.org/10.1111/modl.12085

Young, D. J. (1991). Creating a low-anxiety classroom environment: What does language anxiety research suggest? The Modern Language Journal, 75, 426-437. https://doi.org/10.1111/j.1540-4781.1991.tb05378.x

Zhao, A. D., \& Guo, Y. (2013). Foreign language reading anxiety: Chinese as a foreign language in the United States. The Modern Language Journal, 97, 764-778. https://doi.org/10.1111/j.1540-4781.2013.12032.x

Zbornik, J. J., \& Wallbrown, F. H. (1986). The development and validation of a scale to measure reading anxiety. Reading Improvement, 28, 2-13.

\section{Copyrights}

Copyright for this article is retained by the author(s), with first publication rights granted to the journal.

This is an open-access article distributed under the terms and conditions of the Creative Commons Attribution license (http://creativecommons.org/licenses/by/4.0/). 